\title{
Exploring UK attitudes towards unlicensed medicines use: a questionnaire-based study of members of the general public and physicians
}

This article was published in the following Dove Press journal:

International Journal of General Medicine

9 January 2012

Number of times this article has been viewed

\author{
Alison Chisholm \\ Omega Scientific, Yately, UK
}

Correspondence: Alison Chisholm 9 Exeter Gardens, Yateley, Hants, GU46 7RS, UK

Tel +4407936350773

Email alison@omegascientific.co.uk
Aims: To undertake a questionnaire-based study to evaluate attitudes towards the use of unlicensed medicines among prescribing doctors and members of the general public (ie, patients). The study also aimed to explore the factors that influence physicians' prescribing decisions and priorities, and to understand the knowledge of the medicines licensing system among members of the public.

Methods: Novartis Pharmaceuticals UK Ltd funded the online interview of 500 members of the general public and 249 prescribing physicians. Best practice standards were followed for questionnaire-based studies; no specific treatments or conditions were mentioned or discussed.

Results: Few of the participating physicians, only 14\%, were very familiar with the UK General Medical Council (GMC) guidelines on the use of unlicensed medicines and just $17 \%$ felt very comfortable prescribing an unlicensed medication when a licensed alternative was available. Key physician concerns included the lack of safety data (76\%), legal implications (76\%), and safety monitoring associated with unlicensed medicine use (71\%). Patients and physicians agreed that safety and efficacy are the most important prescribing considerations, although $48 \%$ of participating physicians were worried that budget pressures may increase pressure to prescribe unlicensed medications on the basis of cost. A high proportion of patients (81\%) also indicated some degree of concern, were they to be prescribed an unlicensed medication when a licensed alternative was available specifically because it costs less.

Conclusions: This UK-based questionnaire study suggests pervasive concerns among prescribers over the safety, monitoring, and legal implications of unlicensed prescribing. High levels of concern were expressed among patients and physicians if cost were to become an influential factor when making decisions between licensed and unlicensed medications.

Keywords: patient, physician, unlicensed treatment, concern, safety, trust

\section{Introduction}

The UK's General Medical Council (GMC) recently issued for consultation draft guidance relaxing their stance on the use of unlicensed medicines. This proposed revised position comes at a time of increased budgetary pressures within the National Health Service (NHS) leading to concerns over increasing pressures to prescribe cheaper therapies irrespective of their license status or the availability of robust safety and efficacy data. Indeed, the UK Department of Health plans to commission expert assessments of the evidence for the use of off-label drugs in the light of estimates that around 1000 specific requests for off-label drug use are made to NHS commissioners in England every year. 
The GMC's existing guidance states that an unlicensed medicine should not be prescribed where a licensed alternative is available. ${ }^{1}$ In contrast, the proposed, new guidance affords physicians greater discretion, allowing them to prescribe off-label, or unlicensed, drugs if no appropriate licensed alternative is available, or if they are satisfied that the unlicensed option is as safe and efficacious. ${ }^{2}$ Irrespective of the change in guidance, physicians are still required to have adequate insurance or indemnity cover should they choose to prescribe unlicensed drugs. ${ }^{2}$ The legal responsibility for the outcome of an unlicensed drug prescription (and patient's aftercare) still resides with the prescriber.

An "unlicensed medicinal product" is one that has not been evaluated by a competent regulatory authority as having an appropriate risk:benefit profile because no regulatory submission has been prepared and considered. There are liabilities that should be considered by all those involved in the prescribing of medicines, ranging from obligations under professional codes of conduct to common law (eg, negligence) and statutory obligations and liabilities under Consumer Protection legislation. ${ }^{3}$

The draft GMC guidance was published shortly after new Quality Outcome Framework (QoF) indicators were introduced, which encourage general practitioners (GPs) to make efficiency savings in prescribing. ${ }^{4}$ The new QoF targets require practices to review their current prescribing behavior to assess its clinical and cost effectiveness. Three areas of improvement must be identified and agreed with the Primary Care Organisation and subsequent payments will be made in line with the percentage of prescriptions issued in the first quarter of 2012 that comply with each of three agreed plans. Against this backdrop, the relaxation of the GMC guidance on unlicensed prescribing may see physicians coming under increased pressure to prescribe cheaper therapies, irrespective of their license status.

To obtain a marketing authorization, drug manufacturers must carry out extensive, costly trials to satisfy regulatory bodies (ie, the European Medicines Agency [EMA] in Europe and the Food and Drug Administration [FDA] in the US) of the medicine's positive safety profile and efficacy compared to existing gold standard therapy. Furthermore, as part of the submission, the manufacturer must also demonstrate an optimal formulation and specify the production techniques and presence of a robust supply chain.

Encouraging and incentivizing physicians to prescribe therapies on the basis of price rather than robust trial data undermines the value of the regulatory process and may, in the long term, discourage drug manufacturers from investing in research and bringing new drugs to the market. In addition to the long-term implications of unlicensed drug use, there are also more immediate concerns over the monitoring of unlicensed drug safety. It is a legal requirement, under EU directive 2001/83, for drug manufacturers to design a pharmacovigilance framework to ensure ongoing monitoring of adverse events. ${ }^{5}$ While the manufacturer has a responsibility to record and report adverse events, safety reports generated following the unlicensed use of a licensed medicine will not be evaluated as part of a formal risk management plan. As a result, important emerging safety signals may be missed.

The GMC's proposed revised stance brings to a head growing concerns in this area. There is now a need for greater understanding of the attitudes towards unlicensed prescribing among prescribers themselves. With the aim of improving knowledge in the area, Novartis Pharmaceuticals UK Ltd commissioned the Exploring UK Attitudes Towards Unlicensed Medicines Use questionnaire-based study to explore physicians' prescribing decisions, priorities and attitudes to off-license prescribing and also the public's knowledge of the medication licensing system, awareness of, and attitudes to, off-license drug use.

\section{Methods}

\section{Data source and patients}

A questionnaire-based study was conducted among physicians and members of the general public (hereafter referred to throughout as "patients") to evaluate attitudes and behavior around use of unlicensed drugs on the NHS. Separate physician and patient questionnaires were devised.

Two hundred and forty-nine $(\mathrm{n}=249)$ medical doctors across a wide variety of medical disciplines took part in online interviews conducted between 3-10 March 2011. The interviews were designed to evaluate prescribers' attitudes and concerns around use of unlicensed drugs and the influence that various factors may or may not have on prescribing decisions and priorities, as well as assessing the impact of the cost-saving challenges currently being faced by the NHS.

Patient questionnaires were conducted between 4-7 March 2011 and involved completion of an online interview by adults living in the UK (aged $\geq 18$ years, $n=500$ ). The questions asked were designed to assess knowledge of, and concerns around, the use of unlicensed drugs among the general population. Information was also captured around patient-physician interactions in terms of drug prescribing and the degree of trust patients have in their physicians. 
To ensure the participating population was representative of the actual population, maximum and minimum quotas were set using the online questionnaire software for key population demographics. For example, once the maximum number of male interviews was met, subsequent questionnaires were only conducted in female participants.

Care was taken to ensure no open-ended questions were asked as part of the questionnaire. The data analysis was based on the numbers captured through the quantitative research. No specific treatments or conditions were mentioned in the course of the interviews. Figures for general population age, sex, and region were weighted where necessary to bring them into line with their actual proportions in the population.

\section{Questionnaires}

For the purposes of the questionnaire, unlicensed prescribing was defined as "prescribing a treatment for a condition for which it has no license, is administered via a different route and/or where a formulation has been changed".

\section{Physician questionnaire}

The physician questionnaire consisted of 18 questions that captured demographic data (see Table 1) and a variety of information relating to attitudes to, and concerns around, unlicensed drug use (see Appendix 1 for the full physician questionnaire).

Table I Summary of physician demographics, specialisms and prescribing powers

\begin{tabular}{ll}
\hline Physician characteristic & N (\%) \\
\hline Total & $249(100 \%)$ \\
Geographical distribution of practices & $209(84 \%)$ \\
England & $14(6 \%)$ \\
Wales & $22(9 \%)$ \\
Scotland & $3(1 \%)$ \\
Northern Ireland & $100(40 \%)$ \\
Primary/secondary care & $149(60 \%)$ \\
Primary & \\
Secondary & $92(38 \%)$ \\
Primary specialty & $12(5 \%)$ \\
General Practice & $20(8 \%)$ \\
Cardiology & $19(8 \%)$ \\
Oncology & $19(8 \%)$ \\
Psychiatry & $19(8 \%)$ \\
Ophthalmology & $12(5 \%)$ \\
Anesthesiology & $19(8 \%)$ \\
Neurology & $19(8 \%)$ \\
Gastroenterology & \\
Other & $249(100 \%)$ \\
Prescribing powers & $0(0 \%)$ \\
Yes & \\
No &
\end{tabular}

General knowledge of the implications of unlicensed prescribing was gauged by asking physicians how familiar they were with the GMC guidelines on unlicensed drug prescribing and how aware they were of their responsibilities if they decided to prescribe off-label.

Prescribing priorities were assessed by asking physicians to rank (1 high: 4 low) a number of factors and questions relating to their prescribing priorities: efficacy, safety, convenience (eg, simplicity of dosing regimen) and cost.

General attitudes to prescribing off-label were captured through a series of questions around the evidence base they believed was necessary to prove the efficacy of a drug (license only, guideline endorsement, anecdotal, peer journals) and how often they consider the licensed treatment option(s) available for a specific condition first (always, sometimes, occasionally, rarely, or never). Degree of comfort prescribing unlicensed treatment was assessed, as were views around which circumstances (if any) justify use of an unlicensed treatment when a licensed alternative is available and areas of concern posed by unlicensed drug prescribing, eg, lack of robust safety data, legal risks, lack of pharmacovigilance.

The physicians were posed questions designed to evaluate the degree to which budgetary pressures within the NHS may affect their prescribing practice in the future and physicians' concerns if they were to come under pressure to prescribe an unlicensed therapy over a licensed alternative specifically to reduce prescribing costs.

\section{Patient questionnaire}

The patient questionnaire consisted of 14 questions that captured demographic data (see Table 2) and information relating to their understanding of the licensing process and perceptions of the use of unlicensed drugs. (See Appendix 2 for the full patient questionnaire.)

Patients were first asked a number of questions designed to capture the patient-physician relationship, eg, the degree of trust they place in their physician's prescribing decisions, whether they seek a second opinion when prescribed a therapy and whether they view prescribing as a collaborative process in which they play a part.

Their knowledge of drug licensing was assessed by asking them to indicate their degree of knowledge of the drug regulatory process (from "a great deal" to "nothing at all"). They were then asked for their level of agreement with a number of statements about when medications can be prescribed, eg, "Doctors can prescribe any medication they choose to treat a condition" and "Medication can be prescribed for a condition if it has been approved for that specific condition." 
Table 2 Summary of patient demographics

\begin{tabular}{ll}
\hline Patient characteristic & N (\%) \\
\hline Total & $500(100 \%)$ \\
Gender (male) & $250(50 \%)$ \\
Age (years) & \\
18-24 & $61(12 \%)$ \\
$25-34$ & $104(21 \%)$ \\
$35-44$ & $113(23 \%)$ \\
$45-54$ & $87(17 \%)$ \\
$\geq 55$ & $135(27 \%)$ \\
Geographical distribution & \\
North East & $29(6 \%)$ \\
North West & $50(10 \%)$ \\
Yorkshire and Humberside & $50(10 \%)$ \\
East Midlands & $42(8 \%)$ \\
West Midlands & $40(8 \%)$ \\
East of England & $44(9 \%)$ \\
London & $55(11 \%)$ \\
South East & $62(12 \%)$ \\
South West & $47(9 \%)$ \\
Wales & $30(6 \%)$ \\
Scotland & $35(7 \%)$ \\
Northern Ireland & $12(2 \%)$ \\
Channel Islands & $2(0.4 \%)$ \\
\hline
\end{tabular}

As for physicians, patients were asked to rank, in order of priority, a number of factors that they believe their physician takes into consideration when making prescribing decisions: (i) "It works" (ie, efficacy); (ii) "It is safe" (ie, safety); (iii) "It is not expensive" (ie, cost); (iv) "It is easy to take or administer" (ie, convenience).

To gauge patients' attitudes towards unlicensed prescribing, patients were asked questions around how they would feel were they prescribed an unlicensed therapy when a licensed alternative was available, when they thought it may be acceptable to prescribe an unlicensed treatment and how concerned they would feel about drug safety if they were prescribed an unlicensed therapy.

\section{Results}

\section{Demographics}

An even mix (50/50) of male and female doctors and patients took part in the study, across a wide age range from 18 to $\geq 55$ years (see Tables 1 and 2 ). $60 \%$ of participating physicians worked in secondary care and $40 \%$ in primary care; all had prescribing rights. ${ }^{6}$

\section{Familiarity with guidelines and processes Physicians' familiarity with the existing GMC guidelines}

There was limited familiarity with the existing GMC guidelines on the use of unlicensed therapies among the physicians (only $14 \%$ very familiar, $42 \%$ somewhat familiar), ${ }^{7}$ but the majority ( $82 \%$ ) knew that any problems that occur following use of an unlicensed treatment are the responsibility of the prescriber. ${ }^{8}$

\section{Patients' familiarity with drug licensing}

There was limited understanding of the drug licensing process in the adults who participated in the study. $69 \%$ of patients indicated that they have little or no awareness of the drug regulatory process and only $8 \%$ said they knew a lot about it (see Figure 1). ${ }^{9}$ Around half (53\%) of participating patients believed medications can only be prescribed for a specific, approved condition. ${ }^{10}$

\section{Evidence base}

There was little consensus among physicians on the required evidence base to confirm the safety of a therapy. The majority $(62 \%)$ believed national or local guidelines to be sufficient proof of safety and $38 \%$ of the group felt that recommendation of drugs by their peers was also a sufficient measure. ${ }^{11}$

\section{Perceived prescribing influences}

The physicians believed the most important consideration when prescribing a therapy was its efficacy data (70\%), followed by its safety (25\%). Cost and convenience (eg, dosing frequency) were less important considerations. ${ }^{12}$ Patients also believed safety and efficacy to be the most important two considerations, but the rank order was reversed with $63 \%$ believing safety and $30 \%$ efficacy to be the greatest prescribing influences (See Figure 2 and Table 3). ${ }^{13}$

Patient and physician views differed most greatly on the factors that least affect prescribing decisions. Almost two-thirds $(64 \%)$ of patients believed cost to be the least important factor when prescribing compared with a lower $43 \%$ of physicians, suggesting physicians may have a greater awareness than patients of the role cost plays in prescribing decisions (see Table 3). ${ }^{12,13}$

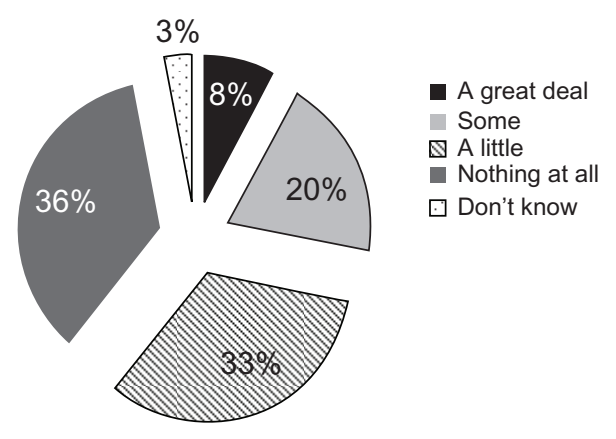

Figure I Knowledge of the drug licensing process among patients.9 


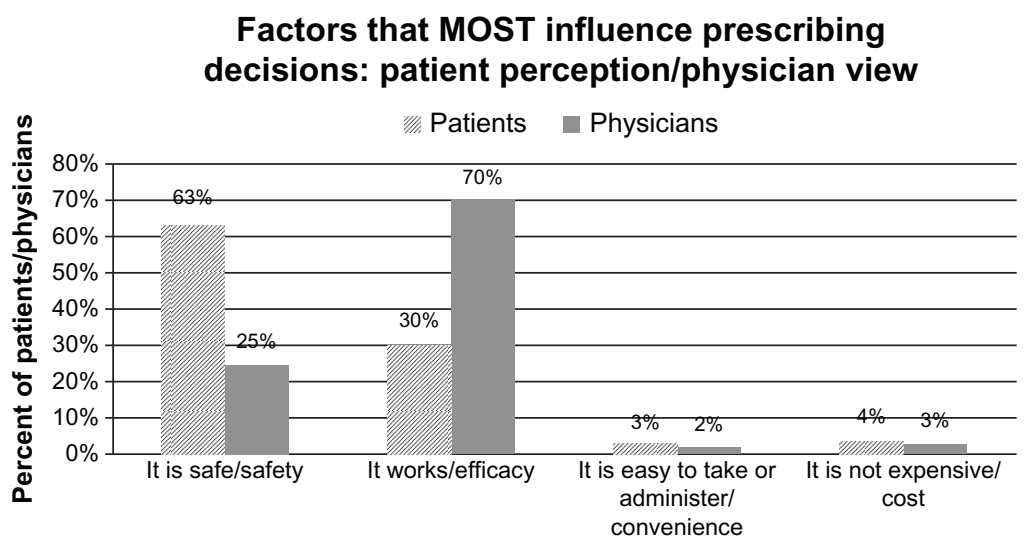

Figure 2 Summary of factors as perceived by patients and physicians and considered by them as the most influential when making prescribing decisions. ${ }^{12,13}$

\section{Attitudes towards unlicensed prescribing Physicians}

$40 \%$ of physicians agreed that it is never appropriate to prescribe an unlicensed treatment if a licensed treatment is available. ${ }^{14}$ Yet unlicensed prescribing does occur and, when questioned, physicians suggested that the main reason for this is the absence of a licensed alternative ( $84 \%$ of physicians) or because the licensed treatment has failed to work $(56 \%$ of physicians) or has more side effects $(40 \%) .{ }^{15}$

Only $17 \%$ of all physicians questioned indicated they would be "very comfortable" prescribing an unlicensed treatment whilst almost one-third (31\%) said they would be "not very", or "not at all comfortable" prescribing off-license. ${ }^{16}$ Confidence in off-label prescribing was markedly lower among primary (7\%) compared with secondary care $(24 \%)$ physicians. ${ }^{16}$ The majority of physicians are at least somewhat concerned about the legal risk (76\%), lack of robust safety data $(76 \%)$, and safety monitoring $(71 \%)$ when it comes to unlicensed prescribing. ${ }^{17}$

\section{Patients}

From a patient perspective, around one-third (38\%) of patients felt unlicensed therapy prescribing was acceptable if a licensed alternative has already been tried, or if the unlicensed medication has fewer side effects (37\%). ${ }^{18}$ If there were no alternative treatment options available, nearly half $(47 \%)$ of patients would be willing to take an unlicensed medication. A similar proportion (43\%) would take unlicensed medication if it had been proven to be more likely to work for their specific condition. ${ }^{18}$ Some patients (17\%), however, would be dissatisfied if prescribed an unlicensed drug over a licensed alternative and $14 \%$ would refuse or stop taking the medication. ${ }^{19}$

\section{The role of cost on prescribing behavior}

\section{Physicians}

The majority (92\%) of participating physicians expected NHS cost savings to have an impact on future prescribing choices. ${ }^{20}$ Almost half (49\%) indicated they were somewhat concerned that they might come under pressure to prescribe unlicensed therapies for cost saving reasons in the future and $83 \%$ are at least somewhat concerned that cost may become the deciding factor in treatment selection. ${ }^{21}$

\section{Patients}

The majority of patients ( $82 \%)$ trust their doctor and similar proportions $(80 \%)$ feel that prescribing decisions are made

Table 3 Distribution of rank scoring across perceived prescribing influences, split by patient- and physician-perceived views ${ }^{12,13}$

\begin{tabular}{|c|c|c|c|c|c|}
\hline Rank score of importance & & Safety & Efficacy & Convenience and ease of administration & Cost \\
\hline \multicolumn{6}{|l|}{ Patient perception } \\
\hline \multirow[t]{3}{*}{ Most important } & I & $63 \%$ & $30 \%$ & $3 \%$ & $4 \%$ \\
\hline & 2 & $29 \%$ & $61 \%$ & $5 \%$ & $5 \%$ \\
\hline & 3 & $4 \%$ & $5 \%$ & $64 \%$ & $27 \%$ \\
\hline Least important & 4 & $4 \%$ & $3 \%$ & $29 \%$ & $64 \%$ \\
\hline \multicolumn{6}{|l|}{ Physician perception } \\
\hline \multirow{3}{*}{ Most important } & I & $25 \%$ & $70 \%$ & $2 \%$ & $3 \%$ \\
\hline & 2 & $64 \%$ & $25 \%$ & $4 \%$ & $7 \%$ \\
\hline & 3 & $8 \%$ & $2 \%$ & $43 \%$ & $46 \%$ \\
\hline Least important & 4 & $3 \%$ & $2 \%$ & $52 \%$ & $43 \%$ \\
\hline
\end{tabular}




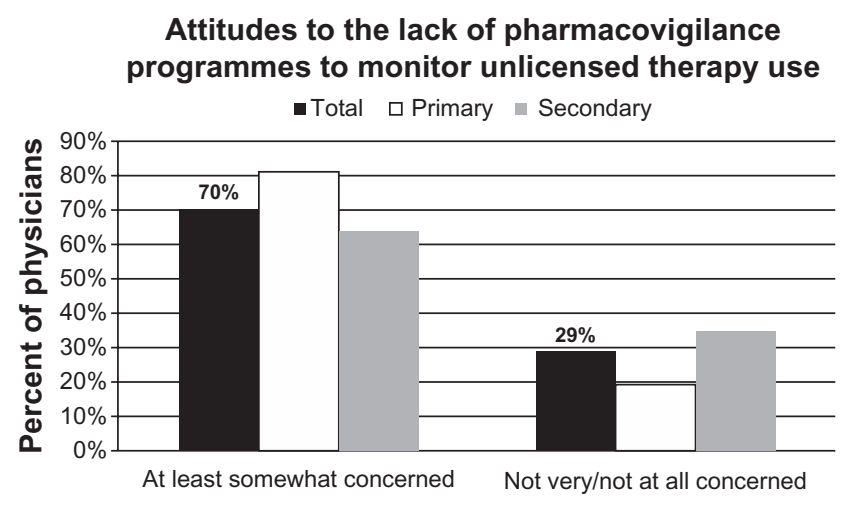

Figure 3 Level of concern among physicians over absence of pharmacovigilance programs for unlicensed therapies, split by place of work (primary/secondary care). ${ }^{24}$

collaboratively between themselves and their physician. ${ }^{22}$ Yet, this trust and collaborative relationship could be challenged if cost becomes a driver of prescribing decisions; $81 \%$ of patients expressed at least some concern $(38 \%$ were "very concerned") about safety if prescribed an unlicensed medication over a licensed medication specifically because it is less costly (see Figure 4). ${ }^{23}$

\section{Discussion}

This UK-based questionnaire study suggests real concern around the safety and pharmacovigilance issues associated with unlicensed drug prescribing. Eighty-one percent $(81 \%)$ of patients expressed at least some concern about safety if prescribed an unlicensed treatment and the majority (76\%) of physicians were at least somewhat concerned about the legal risks, lack of robust safety data, and safety monitoring of unlicensed prescribing. ${ }^{1723}$ Only $17 \%$ of physicians indicated they would be very comfortable to prescribe unlicensed therapy over a licensed alternative. ${ }^{16}$

UK patients currently place a high degree of trust in their physicians' prescribing decisions and the majority believe

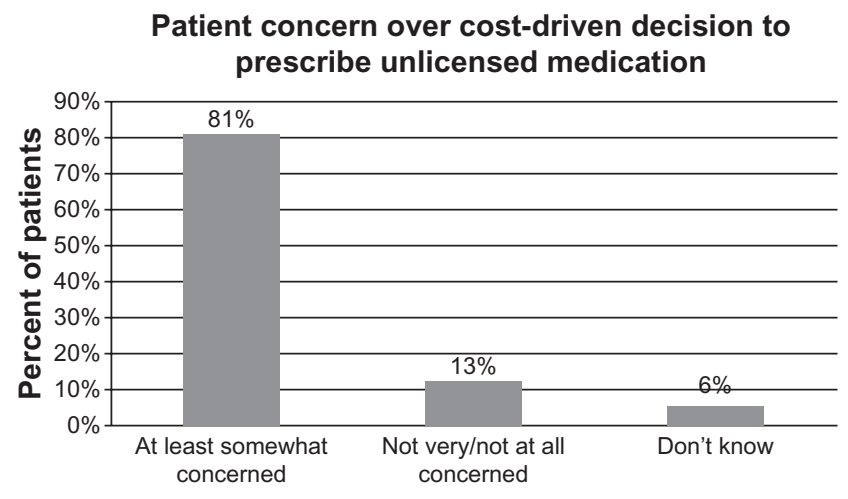

Figure 4 Aggregated distribution of concern if the patient's physician prescribed them an unlicensed therapy over a licensed alternative because of cost reasons. ${ }^{23}$ prescribing decisions are made collaboratively between themselves and their physician. Yet patients can only challenge unlicensed drug prescribing if they are aware of drug licensing issues and over two-thirds (69\%) of patients have little or no awareness of the drug regulatory process. ${ }^{9}$

Across both patients and physicians, cost was perceived to be the least important factor when deciding whether to prescribe an unlicensed therapy when a licensed alternative was available. However, a lower percentage of physicians (compared with patients) ranked it as the least important factor, perhaps suggesting a greater awareness among physicians of the influence budgetary pressures currently play. ${ }^{12,13}$ This interpretation is supported by the high proportion (92\%) of physicians who expect cost to become an increasingly important factor when prescribing and the high levels of concern (83\% of physicians at least somewhat concerned) that cost will become the deciding factor. ${ }^{20,21}$

The strengths of this study include the large, geographically diverse patient population and the multidisciplinary nature of the participating physicians. No drugs were mentioned in the course of the patient or physician questioning allowing objective opinions to be captured. Study limitations that could be resolved in a larger evaluation of this kind include the lack of data from physicians in any one specialism, geographical location, or age group to compare differing trends in physician response by age, geography, and specialism.

In conclusion, there is little patient knowledge of the drug licensing process and limited physician familiarity with the GMC guidance on unlicensed drug prescribing. Patients and physicians agreed that safety and efficacy are the most important factors to consider when making prescribing decisions and unlicensed prescribing, on the basis of cost, raised concerns for both groups. The current environment within the NHS, however, means a high proportion of physicians are concerned that cost pressures on prescribing will continue to increase and may become the deciding factor. A larger study of this sort in the future would allow further analysis of predictors of physician attitudes and an evaluation of whether physicians' current concerns become a reality and the effect this may have on the patient-physician relationship.

\section{Acknowledgments/disclosure}

This study was conducted by KRC Research, funded by Novartis Pharmaceuticals UK Ltd, and no specific treatments or conditions were mentioned or discussed. This publication was authored independently and has been reviewed by Novartis. The author has no conflicts of interest to declare. 


\section{References}

1. General Medical Council. Guidelines on Good practice in prescribing medicines - guidance for doctors. September 2008. Available at: http:// www.gmc-uk.org/guidance/ethical_guidance/prescriptions_faqs.asp\#9. Last accessed October 14, 2011.

2. General Medical Council. Good practice in prescribing and managing medicines and devices - Draft for consultation. Available at: http://www. gmc-uk.org/Good_practice_prescribing_consultation_draft_FINAL. pdf_40006888.pdf. Last accessed November 11, 2011.

3. Department of Trade and Industry. European Product Liability Directive and Part 1 Consumer Protection Act 1987. Available at: http://www. legislation.gov.uk/ukpga/1987/43/pdfs/ukpga_19870043_en.pdf. Last accessed November 9, 2011.

4. British Medical Association and NHS Employers. QOF Quality and Productivity (QP) Indicators. May 2011. Available at: http://www. nhsemployers.org/SiteCollectionDocuments/QP_supplementary_guidance_and_FAQs_bt270511.pdf. Last accessed November 1, 2011.

5. European Parliament and the Council. Directive 2001/83/EC of the European Parliament of the Council of November 6, 2001 on the Community Code Relating to Medicinal Products for Human Use. Available at: http://www.emea.europa.eu/docs/en_GB/document_library/ Regulatory_and_procedural_guideline/2009/10/WC500004481.pdf. Last accessed November 2, 2011.

6. KRC Unlicensed Medicines Use Survey (prescriber arm) conducted March 2011.

7. Q10 KRC Unlicensed Medicines Use Survey (prescriber arm) conducted March 2011

8. Q11 KRC Unlicensed Medicines Use Survey (prescriber arm) conducted March 2011.

9. Q7 KRC Unlicensed Medicines Use Survey (general public arm) conducted March 2011.
10. Q6 KRC Unlicensed Medicines Use Survey (general public arm) conducted March 2011.

11. Q2 KRC Unlicensed Medicines Use Survey (prescriber arm) conducted March 2011.

12. Q1 KRC Unlicensed Medicines Use Survey (prescriber arm) conducted March 2011.

13. Q8 KRC Unlicensed Medicines Use Survey (general public arm) conducted March 2011.

14. Q6 KRC Unlicensed Medicines Use Survey (prescriber arm) conducted March 2011.

15. Q5 KRC Unlicensed Medicines Use Survey (prescriber arm) conducted March 2011.

16. Q4 KRC Unlicensed Medicines Use Survey (prescriber arm) conducted March 2011.

17. Q7-9 KRC Unlicensed Medicines Use Survey (prescriber arm) conducted March 2011.

18. Q9 KRC Unlicensed Medicines Use Survey (general public arm) conducted March 2011.

19. Q10 KRC Unlicensed Medicines Use Survey (general public arm) conducted March 2011.

20. Q12 KRC Unlicensed Medicines Use Survey (prescriber arm) conducted March 2011.

21. Q13-15 KRC Unlicensed Medicines Use Survey (prescriber arm) conducted March 2011.

22. Q4-7 KRC Unlicensed Medicines Use Survey (general public arm) conducted March 2011.

23. Q11 KRC Unlicensed Medicines Use Survey (general public arm) conducted March 2011.

24. Q9 KRC Unlicensed Medicines Use Survey (prescriber arm) conducted March 2011. 


\section{Appendix \\ Novartis study: exploring UK attitudes towards licensed medicines use FINAL}

\section{Parameters}

Recruitment criteria and sample stratification:

- Physicians (medical doctors) who have prescribing responsibilities - 200 interviews

- General population (age 18+ years) - 500 interviews

Questionnaire length:

- 5-minute questionnaire (generally allows for 10-15 question items)

Method:

- Online (opted-in panels)

Objectives:

- Determine whether physicians are comfortable prescribing unlicensed drugs, what factors determine their prescribing behavior, whether they have concerns about the use of unlicensed drugs, and whether they expect the NHS cost-saving drive to affect their prescribing habits.

- Establish whether the general public have concerns about, or even familiarity with, unlicensed drugs, and their reported interactions with their physician when it comes to prescriptions.

\section{Introduction}

Thank you for participating in this brief survey. This survey is strictly for research purposes, and should take no more than 10 minutes of your time. It is not intended to promote the sale of any product or device, and you will not be contacted for marketing purposes as a result of participating. Your responses will be kept confidential and anonymous, and nothing you say will be attributed to you personally.

\section{Appendix I}

\section{Physician survey}

We are now being asked to pass on to our client, details of adverse events that are mentioned during the course of market research. Although all your responses will, of course, be treated in confidence and anonymously, should you raise during the interview an adverse event in a specific patient, we will need to report this, even if it has already been reported by you directly to the company or the regulatory authorities using the MHRA's 'Yellow Card' system.

In such a situation, you will be asked whether or not you are willing to waive the confidentiality given to you under the Market Research Code of Conduct specifically in relation to that adverse event. Everything else you mention during the course of the interview will continue to remain confidential, and you will still have the option to remain anonymous if you so wish.

Are you happy to proceed on this basis?

Yes - Continue

No - Thank you and close

First, some questions to confirm that you qualify for the study:

\section{Physician screening}

1. Where do you practice?

England.

Wales .......

Scotland.......

Northern Ireland

None of these.

2. Do you currently have prescribing responsibilities?

Yes

No. 
3. Are you involved in primary or secondary care?

Primary..... 1

Secondary 2

In the survey below we will be asking for your opinion on scenarios related to prescribing and the use of unlicensed treatments. When referring to a treatment being unlicensed, we will be using the following definition:

Without a marketing authorization (unlicensed) in the UK for a specific condition or if used with a variation in its licensed formulation or administration.

Throughout this survey, we understand that there are some difficult questions or grey areas. Please answer all questions to the best of your ability.

\section{Physician main survey}

4. Below is a list of factors that you may or may not consider when selecting a treatment to prescribe for a specific condition. In general, how important are each of the following factors when prescribing a treatment? Please rank each of the factors below from 1 to 4 , where 1 means it is the most important, 2 is the second most important, and so on. You can only use each number from 1 to 4 once. [RANDOMIZE ORDER OF ITEMS]

Note: We understand that the factors below are not the only ones to be considered. However, please answer to the best of your ability based on the factors listed below.

The proven efficacy of the treatment for that condition

The proven safety profile of the treatment for that condition.

The treatment cost

The convenience of the treatment (eg, once daily dosing)

Do not agree with any of the above.

5. When considering the safety of the treatments you might prescribe for a particular condition, with which of the following statements do you agree? (MULTIPLE RESPONSES ACCEPTED)

Only a license for use in the specific condition for which I am prescribing treatment provides sufficient evidence of safety

A license for use in any condition provides sufficient evidence of safety ............................................................ 2

National or local prescribing guidelines (including NICE) provide sufficient evidence of safety, regardless of licensing

Peer recommendation (including in journals) or personal experience provides sufficient evidence of safety, regardless

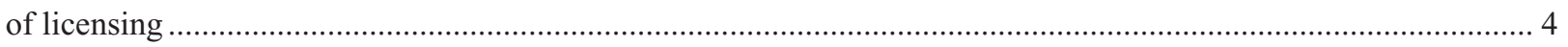

I do not agree with any of these statements (ACCEPT NO OTHER RESPONSES)

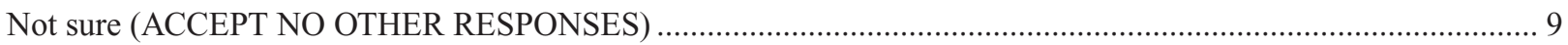

6. When you come to prescribing, how often do you consider the licensed treatment option(s) available for the specific condition first?

Always

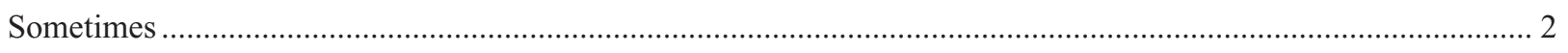

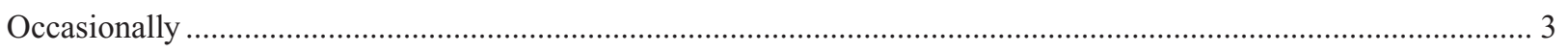

Rarely

Never

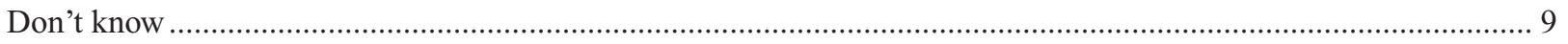

7. Generally speaking, please indicate how comfortable you are prescribing an 'unlicensed' treatment (prescribing a treatment for a condition for which it has no license, is administered via a different route and/or formulation has been changed). 
Very comfortable 1

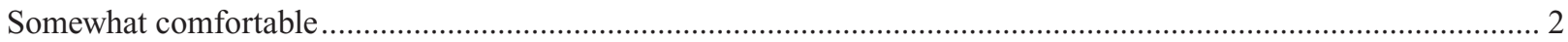

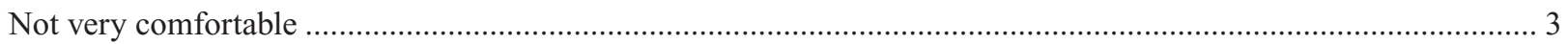

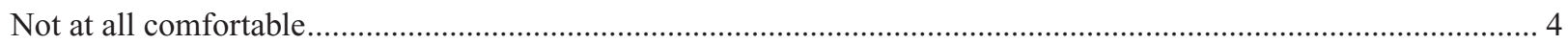

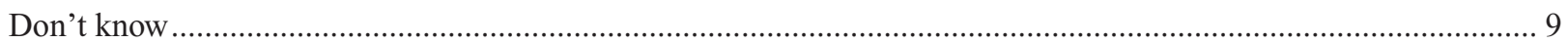

8. In your opinion, which of the following, if any, do you believe are good reasons to select an unlicensed treatment over a licensed treatment for a specific condition? Please select all that apply. [RANDOMIZE. ACCEPT MULTIPLE RESPONSES.]

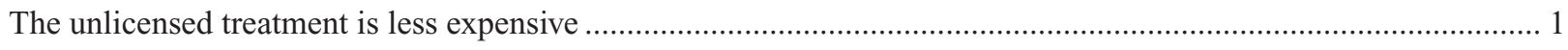

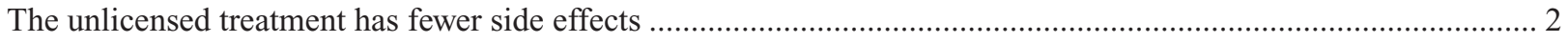

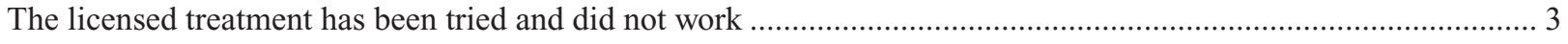

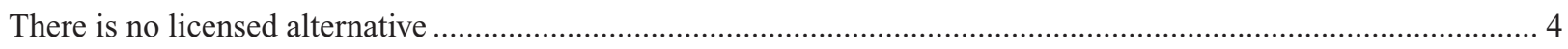

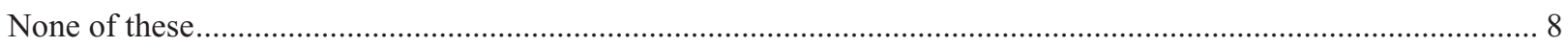

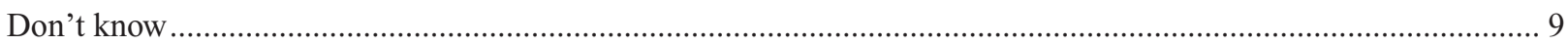

9. To what extent do you agree or disagree with the following statement? [ACCEPT SINGLE RESPONSE.]

It is never appropriate to prescribe an unlicensed treatment if a licensed treatment is available

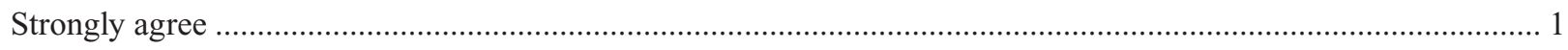

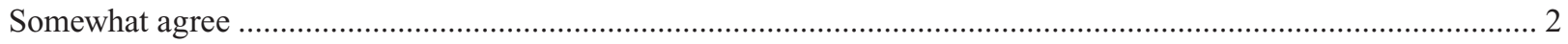

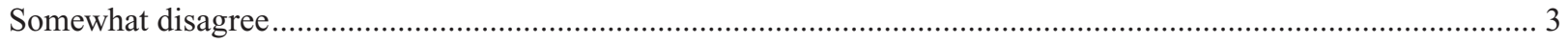

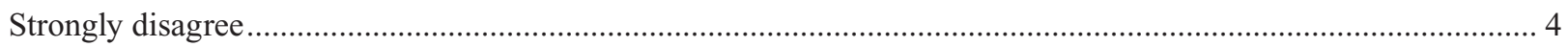

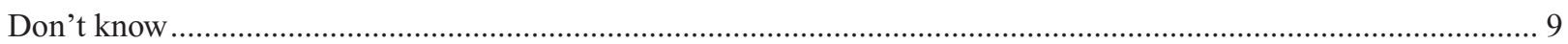

To what extent are you concerned with each of the following when it comes to prescribing unlicensed medications? (RANDOMIZE)

10. That robust safety data are available only

$\begin{array}{lllll}\begin{array}{l}\text { Very } \\ \text { concerned }\end{array} & \begin{array}{l}\text { Somewhat } \\ \text { concerned }\end{array} & \begin{array}{l}\text { Not very } \\ \text { concerned }\end{array} & \begin{array}{l}\text { Not at all } \\ \text { concerned }\end{array} & \begin{array}{l}\text { Don't } \\ \text { know }\end{array} \\ 1 & 2 & 3 & 4 & 9\end{array}$
for licensed conditions, and not always available for unlicensed conditions.

11. That prescribing unlicensed treatments could pose legal risks.

12. That treatment safety monitoring (pharmacovigilance) programmes are only in place for licensed conditions, and not for unlicensed conditions.

13. Before today, how familiar would you say you were with the following GMC guidelines regarding prescribing unlicensed treatments?

"An unlicensed drug should not be used in a condition where a licensed drug is available. When an unlicensed medicine is used, it raises questions on how reporting, interpretation, and the management of adverse events will be undertaken"

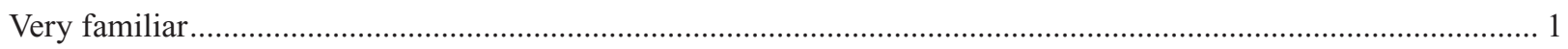

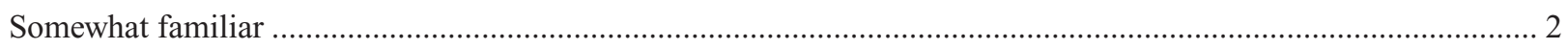

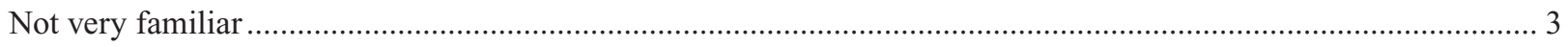

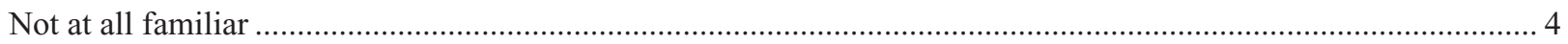

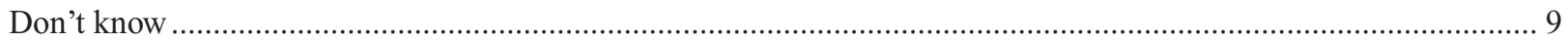

14. Who, if anyone, do you think would be held responsible if a problem occurred following the use of an unlicensed treatment? Please select all that apply. [RANDOMIZE. ACCEPT MULTIPLE RESPONSES.] 


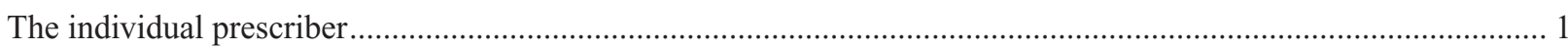

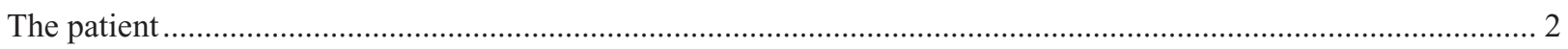

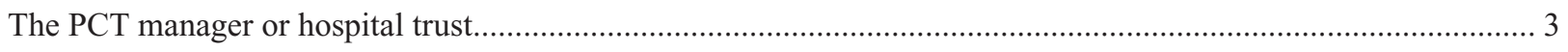

The lead physician responsible for a patient s care .................................................................................. 4

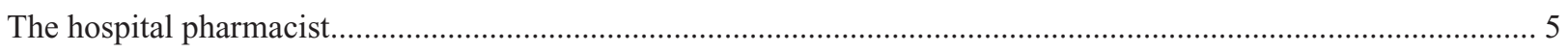

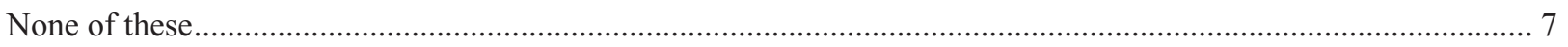

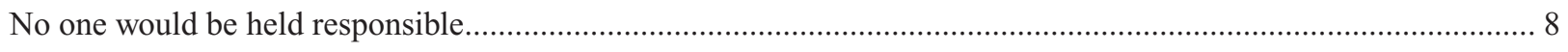

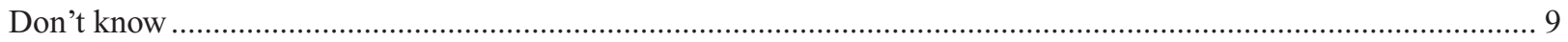

In the current economic climate, the National Health Service is being challenged to identify areas where cost savings can be found. Within this, expenditure on drugs has been identified as one route to reducing annual NHS expenditure.

15. What impact, if any, do you think the current NHS focus on cost saving will personally have on your prescribing choices:

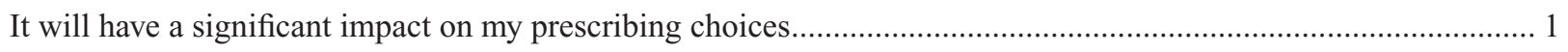

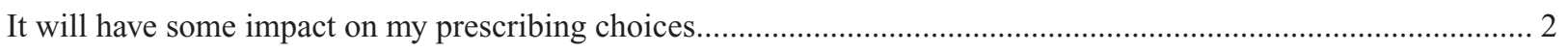

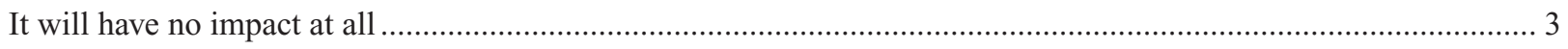

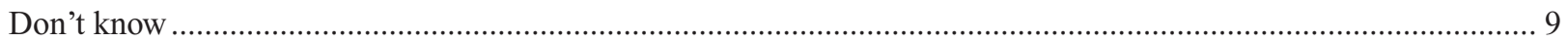

Taking into account the aforementioned anticipated changes to the NHS expenditure on drugs, to what extent are you concerned with each of the following when it comes to using unlicensed medication? (RANDOMIZE)

$\begin{array}{llllll} & \begin{array}{l}\text { Very } \\ \text { concerned }\end{array} & \begin{array}{l}\text { Somewhat } \\ \text { concerned }\end{array} & \begin{array}{l}\text { Not very } \\ \text { concerned }\end{array} & \begin{array}{l}\text { Not at all } \\ \text { concerned }\end{array} & \begin{array}{l}\text { Don't } \\ \text { know }\end{array} \\ \begin{array}{l}\text { 16. Unlicensed medicines might be } \\ \text { increasingly selected over licensed } \\ \text { medicines for cost-saving reasons. }\end{array} & 1 & 2 & 3 & 4 & 9 \\ \begin{array}{l}\text { 17. Cost might become the deciding factor } \\ \text { in treatment selection. }\end{array} & 1 & 2 & 3 & 4 & 9 \\ \begin{array}{l}\text { 18. I might come under pressure to prescribe } \\ \text { an unlicensed treatment for a specific } \\ \text { condition, purely for cost reasons. }\end{array} & 1 & 2 & 3 & 4 & 9\end{array}$

\section{Appendix 2}

\section{General population survey}

Thank you for participating in this brief survey. This survey is strictly for research purposes, and should take no more than 10 minutes of your time. It is not intended to promote the sale of any product or device, and you will not be contacted for marketing purposes as a result of participating. Your responses will be kept confidential and anonymous, and nothing you say will be attributed to you personally.

It is required that we pass on details of adverse events that are mentioned during the course of market research. (By "adverse events", we mean side effects or other consequences of your treatment or medication.) Although all your responses will, of course, be treated in confidence and anonymously, should you mention an adverse event during the interview, we will need to report this, even if it has already been reported by you directly to your physician, to the manufacturer, or to any regulatory authority.

In such a situation you will be asked whether or not you are willing to waive the confidentiality given to you under the Market Research Code of Conduct specifically in relation to that adverse event. Everything else you mention during the course of the interview will continue to remain confidential, and you will still have the option to remain anonymous if you so wish.

Are you happy to proceed on this basis?

Yes - Continue

No - Thank you and close

First, some questions to confirm that you qualify for the study. 


\section{Screening (needed for eligibility and also quotas)}

19. Are you...?

Male. 1

Female .

20. What is your current age? [TERMINATE IF NOT AGE 18+.]

Enter your age here: years old

21. Where do you live?

North East. 1

North West 2

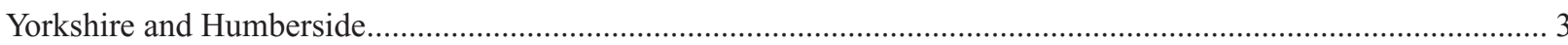

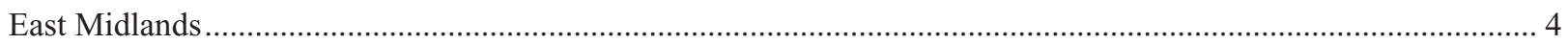

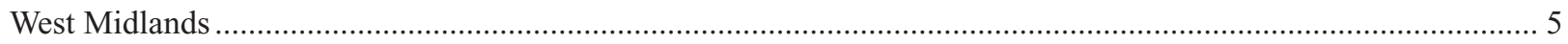

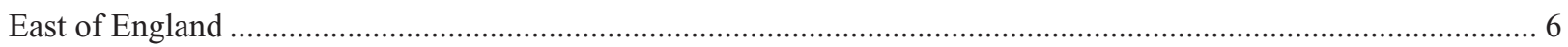

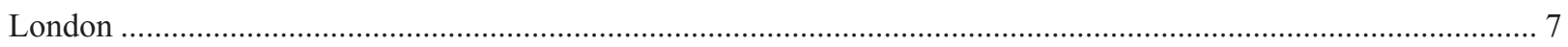

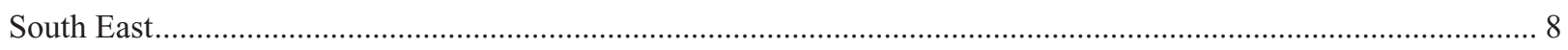

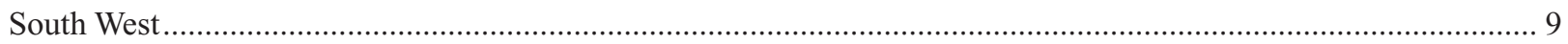

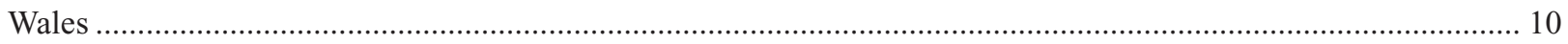

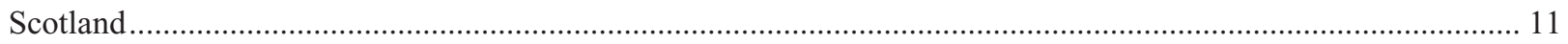

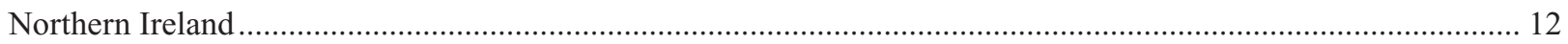

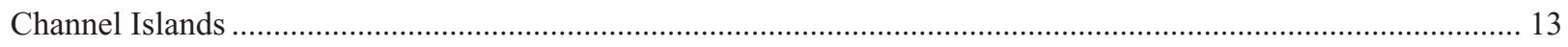

None of these...

[TERMINATE]

\section{General population main survey}

To what extent do you agree or disagree with each of the following statements? [RANDOMIZE]

22. I generally trust the decisions my doctor makes without question.

23. I view making decisions with my doctor as a collaborative process.

24. I always carry out my own research on anything my doctor prescribes me.

25. I always seek a second opinion before following the doctor's instructions.

$\begin{array}{lllll}\begin{array}{l}\text { Completely } \\ \text { agree }\end{array} & \begin{array}{l}\text { Somewhat } \\ \text { agree }\end{array} & \begin{array}{l}\text { Somewhat } \\ \text { disagree }\end{array} & \begin{array}{l}\text { Completely } \\ \text { disagree }\end{array} & \begin{array}{l}\text { Don't } \\ \text { know }\end{array} \\ 1 & 2 & 3 & 4 & 9\end{array}$

$\begin{array}{lllll}1 & 2 & 3 & 4 & 9\end{array}$

$\begin{array}{lllll}1 & 2 & 3 & 4 & 9\end{array}$

$\begin{array}{lllll}1 & 2 & 3 & 4 & 9\end{array}$

26. When your doctor prescribes medication to you, how often do you ask questions about the medication?

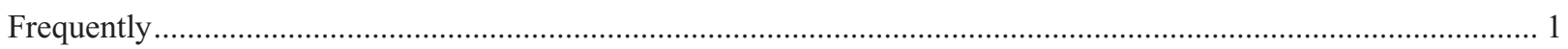

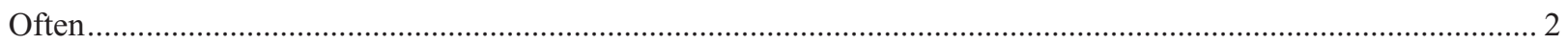

Rarely ...w.

Never

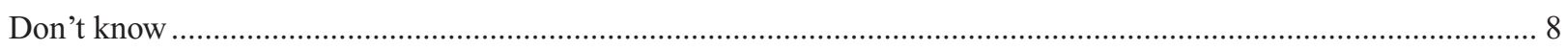

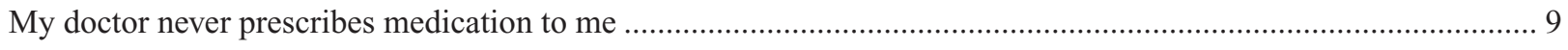


27. Which of the following comes closest to your opinion, to the best of your knowledge? (RANDOMIZE FIRST TWO OPTIONS)

Doctors can prescribe any medication they choose to treat a condition ...... 1

Medication can only be prescribed for a condition if it has been approved for that specific condition.....

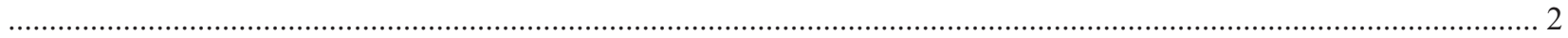

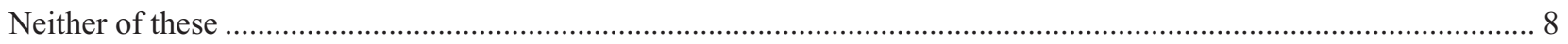

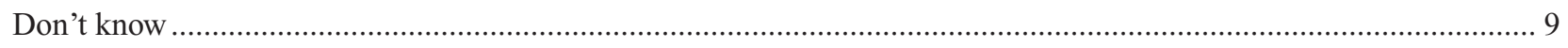

To receive a license for use in a particular condition, medicines must undergo strict regulatory processes. Once licensed, they continue to be subject to the UK's safety monitoring and reporting procedures.

If a medicine is used outside of its license (for a medical condition for which it doesn't have a license), it is not subject to the same robust safety procedures.

28. How much would you say you know about the regulatory process that all medications need to go through to gain a license to be prescribed to patients?

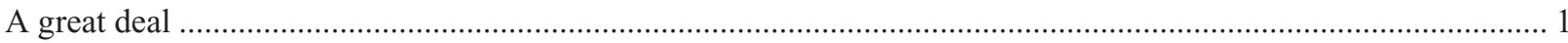

Some

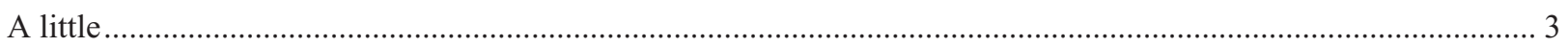

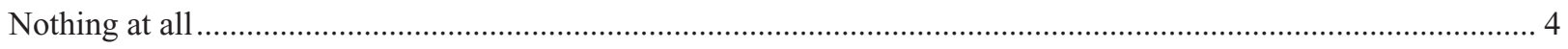

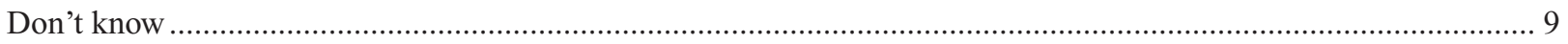

29. When your doctor prescribes medication for you, what do you think are the most important factors about the medication that your doctor should consider.

Please rank each of the factors below from 1 to 4 , where 1 means it is the most important, 2 is the second most important, and so on. You can only use each number from 1 to 4 once. [RANDOMIZE ORDER OF ITEMS]

It works

It is safe

It is not expensive

It is easy to take or administer

30. To the best of your knowledge, in which of the following situations would you think it acceptable for a doctor to prescribe you with a medication that wasn't approved for a particular condition you might have (unlicensed) rather than medication licensed and approved for use for the condition (licensed)? Please select all that apply. [RANDOMIZE. ACCEPT MULTIPLE RESPONSES.]

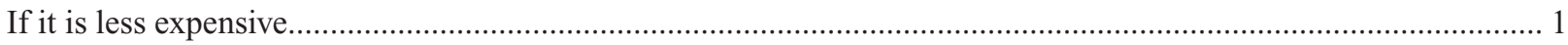

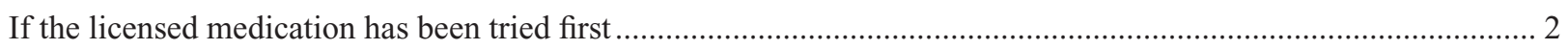

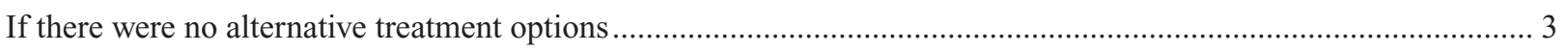

If it is proven to be more likely to work for me than the licensed medication ......................................................... 4

If it is proven to have fewer side effects than the licensed medication ............................................................... 5

None of these

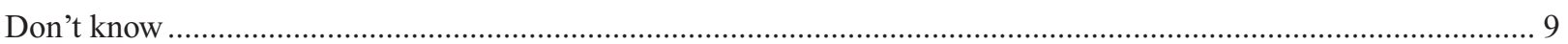

31. If you were prescribed an unlicensed treatment when a licensed treatment is available, how would you feel? Please select all that apply. (RANDOMIZE.)

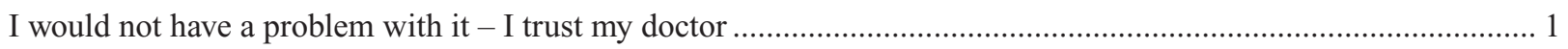

I would ask some follow up questions to learn more, then make a decision ……................................................... 2

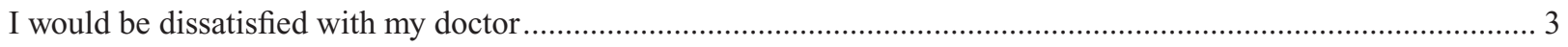

I would stop taking or refuse to take the treatment immediately ......................................................................... 4

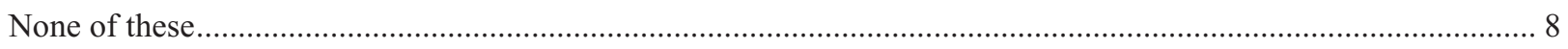

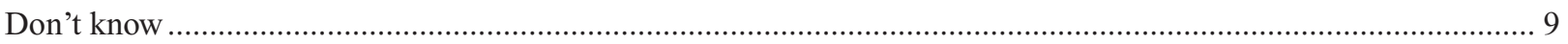


32. If your doctor prescribed you a treatment that is not licensed for your specific condition, specifically because it costs less that a licensed alternative, how concerned would you be about its safety?

Very concerned.

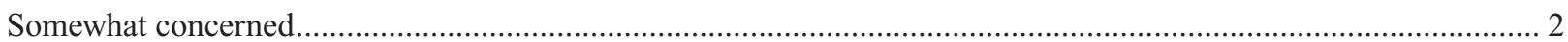

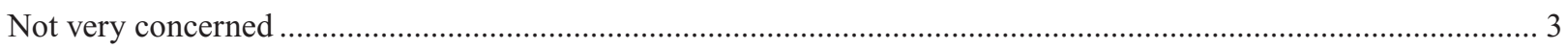

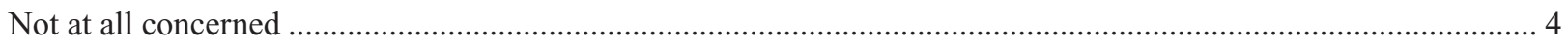

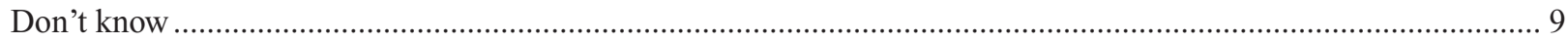

\section{Publish your work in this journal}

The International Journal of General Medicine is an international, peer-reviewed open-access journal that focuses on general and internal medicine, pathogenesis, epidemiology, diagnosis, monitoring and treatment protocols. The journal is characterized by the rapid reporting of reviews, original research and clinical studies across all disease areas.
A key focus is the elucidation of disease processes and management protocols resulting in improved outcomes for the patient.The manuscript management system is completely online and includes a very quick and fair peer-review system. Visit http://www.dovepress.com/ testimonials.php to read real quotes from published authors.

Submit your manuscript here: http://www.dovepress.com/international-journal-of-general-medicine-journal 